\title{
Application of the Health Belief Model on the intention to stop smoking behavior among young adult women
}

\author{
Eko Teguh Pribadi, ${ }^{1}$ Shrimarti Rukmini Devy ${ }^{2}$ \\ ${ }^{1}$ Doctoral Program of Public Health; ${ }^{2}$ Department of Health Promotion and Behavioral Sciences, Faculty of \\ Public Health, Universitas Airlangga, Mulyorejo, Surabaya, Indonesia
}

\begin{abstract}
Background: The smoking behavior among young adult women causes health issues and has effects on ethical norms, especially femininity and gender. A woman smoker usually has an intention to quit and several factors have been perceived to be related to this action according to the Health Belief Model (HBM).

Design and Methods: This study was conducted cross-sectionally to analyze the correlation between young adult women's intention to stop smoking with perceived factors in the construction of HBM. A sample of 58 young adult women smokers and aged between 15-30 years were selected through the use of a purposive sampling technique in 2018.

Results: The results showed the intention to stop smoking has a significant correlation with perceived susceptibility $(\mathrm{P}=0.036)$, perceived severity $(\mathrm{P}=0.028)$, perceived benefits $(\mathrm{P}=0.011)$, perceived barriers $(\mathrm{P}=0.003)$, and perceived self-efficacy $(\mathrm{P}=0.005)$. This means there was a significant correlation between the intention of young adult smokers to quit smoking and the perceived factors of HBM.

Conclusions: The intention of stop smoking behavior among women smokers has a significant correlation with the perceived factors of the Health Belief Model construct, which includes perceived susceptibility, perceived severity, perceived benefits, perceived barriers, and perceived self-efficacy.
\end{abstract}

\section{Introduction}

Women smokers are one of the problems several countries in the world are facing and this is mainly due to the health consequences of smoking and its effect in relation to ethical norms, especially concerning femininity and gender in communities with high reference for eastern tradition. In Indonesia, although smoking behavior is generally found among men, nowadays this behavior is often found in women. Perkins ${ }^{1}$ suggested that women's smoking behavior is less motivated by nicotine seeking and more driven by environmental cues. Cultural shifts, and changes in social values as a direct result of modernization, will be followed by changes in the women's roles in society.
These changes also included the repositioning of women within the framework of social and health behavior, including smoking behavior. Based on the Global Adults Tobacco Survey (GATS), in 2011 Indonesia had the highest number of active smokers, with the prevalence among: $67 \%$ or 57.6 million man against $2.7 \%$ or 2.3 million women. In 2015 , male smokers aged $\geq 15$ were recorded to be $67 \%$ while their female counterparts were $4 \%$. Another survey by The Global Youth Tobacco Survey (GYTS) in 2014 found that $20.3 \%$ of schoolchildren aged 13-16 years smoke with the men covering $36 \%$, while women were $4.3 \%{ }^{2,3,4}$ Indonesia Basic Health Research (RISKESDAS) 2018 noted the proportion of women smokers aged $\geq 15$ years has been fluctuating over the years: in 2007 it was $5.2 \%$, reduced to $4.1 \%$ in 2010 , increased to $6.7 \%$ in 2013 , dropped to $2.5 \%$ in 2016 , and increased again to $4.8 \%$ in 2018 . Smokers spanned through different social classes, status, gender, and age. The major causes of smoking behavior are due to the availability of cigarettes everywhere in the country. Despite the enactment of regional regulations on No-Smoking Areas (KTR) and Limited Smoking Areas (KTM), the prevalence of smokers in the country has not reduced. Furthermore, the number of smokers aged $\geq 15$ years including young adult women in the city of Surabaya was reported to be statistic at $27 \%$ or approximately 776.169 from a total population of 2.874 .699 .5

Several studies have reported women smokers are at higher risk of diseases associated with smoking in comparison to their men counterparts. Although smoking increases the risk of coronary heart disease for both genders, women who smoke tend to have a $25 \%$ greater increased risk of coronary heart disease. Moreover, in addition to general problems such as heart disease, lung cancer, and Chronic Obstructive Pulmonary Disease (COPD), women smokers are more susceptible to breast cancer compared to women who never smoke. A prospective cohort study among postmenopausal women in the USA reported about $9 \%$ and $16 \%$ increased risk of breast cancer among former smokers and current smokers compared with non-smokers. Furthermore, experts believed women that actively smoke tobacco have more risk of premature ovarian failure, indicated by the fact that women smokers enter menopause on average 1.5-2 years earlier than nonsmokers. Smoking has a more transient toxic effect on fertility. Current smokers women but not past smokers had a markedly reduced pregnancy rate compared with non-smokers women. ${ }^{6-10}$

Significance for public health

Women smokers have a high tendency of wanting to quit based on self-encouragement as well as the pressure from the surrounding social environment. The encouragement can be in the form of awareness of illnesses and diseases caused by smoking or other reasons relating to gender. This paper describes the correlation of these factors and their influence on the desire of young adult women smokers to quit smoking were analyzed through the construction of the Health Belief Model (HBM). 
The factors influencing smoking behavior among young adult women include the desire to be accepted and become part of a group of peers, parents or family members currently smoking, strong desire to try cigarettes, glamorous media advertisements on cigarettes, and the belief that smoking is not harmful to the health. ${ }^{11}$ Other studies reported smoking behavior is influenced by three main factors including social, psychological, and environmental factors. ${ }^{12}$ However, women smokers have a high tendency of wanting to quit based on self-encouragement. The encouragement can be in the form of awareness of illnesses and diseases caused by smoking or other reasons relating to gender and social environment. Therefore, the formation of these factors and their influence on the desire of women smokers to quit were analyzed through the construction of the Health Belief Model.

\section{Design and Methods}

This study used a cross-sectional design to analyze the correlation between the factors influencing the intention to stop smoking behavior among young adult women in the city of Surabaya with the factors on the construction of the Health Belief Model through the use of five perceived individual beliefs acting as variables. ${ }^{13}$ Perceived Susceptibility involves the perception on both health and social impact vulnerabilities associated with their smoking behavior, Perceived Severity involves the seriousness of the negative impacts on health, Perceived Benefits is concerned with the benefits of quitting from a health or social perspective, Perceived Barriers is the perception of potential obstacles stopping while Perceived Self-Efficacy is the measure of the self-ability to stop smoking. Respondents were 58 young active smokers adult women aged between 15-30 years and willing to sign Informed Consent form selected through the use of a purposive sampling technique conducted in the city of Surabaya in 2018. Data were collected using a closed questionnaire to measure the five independent variables, and subsequently their correlation was tested with the dependent variable, that is, the intention to stop smoking, through the use of Spearman Rank Correlation.

\section{Results and Discussion}

Table 1 shows the distribution of respondent's characteristics, smoking patterns, and also the distribution of perceived factors and intention. The majority of respondents were between 24-25 years with the average educational level of education was bachelor's degree. On average, they have been smoking at 9 sticks of cigarettes each day for 3-4 years. Most of them have smokers family members, especially fathers, and also smokers friends. Furthermore, the results of the Spearman's Rank Test conducted at $\alpha=0.05(5 \%)$ on the correlation between each variable of the perceived factors and the variable of the intention to stop smoking behavior are shown in Table 2 below.

As it can be seen in Table 2, the variable of Perceived Susceptibility, Severity, Benefits, and Self-Efficacy all have a weak positive correlation to the intention to stop smoking behavior with Sig. (2-Tailed) value of 0.036, 0.028, 0.011, and $0.005<0.05$ respectively, while the Perceived Barriers variable has a weak negative correlation with Sig. (2-Tailed) value $0.003<0.05$.

The results showed the Perceived Susceptibility based on the health and social impacts of smoking has a significant correlation

Table 1. Mean, Standard Deviation of variables.

\begin{tabular}{|c|c|c|c|c|c|c|}
\hline Categories & N & Min. & Max. & Mean & Median & Std. Deviation \\
\hline Age & 58 & 16 & 30 & 24.16 & 25.00 & 3.422 \\
\hline Education & 58 & 2 & 5 & 4.45 & $5 . .00$ & 0.902 \\
\hline Smoking frequency & 58 & 1 & 24 & 8.90 & 6.00 & 5.982 \\
\hline Smoking periods & 58 & 1 & 6 & 3.21 & 3.00 & 1.424 \\
\hline Smoking family & 58 & 1 & 2 & 1.10 & 1.00 & 0.307 \\
\hline Smoking friends & 58 & 1 & 2 & 1.05 & 1.00 & 0.223 \\
\hline Perceived Susceptibility & 58 & 1 & 3 & 1.41 & 1.00 & 0.676 \\
\hline Perceived Severity & 58 & 1 & 3 & 1.47 & 1.00 & 0.706 \\
\hline Perceived Benefits & 58 & 1 & 3 & 1.62 & 1.00 & 0.768 \\
\hline Perceived Barriers & 58 & 1 & 3 & 2.43 & 3.00 & 0.752 \\
\hline Perceived Self-Efficacy & 58 & 1 & 3 & 1.33 & 1.00 & 0.604 \\
\hline Stop smoking intention & 58 & 1 & 3 & 1.45 & 1.00 & 0.680 \\
\hline
\end{tabular}

Table 2. Correlation between perceived variables and stop smoking intention.

\begin{tabular}{lcccc} 
Variables & Significances & $\begin{array}{c}\text { Stop smoking intention }(\mathrm{N}=58) \\
\text { Correlation coefficient }\end{array}$ \\
Perceived Susceptibility & 0.036 & 0.276 & Weak positive correlation \\
Perceived Severity & 0.028 & 0.289 & Weak positive correlation \\
\hline Perceived Benefits & 0.011 & 0.331 & Weak positive correlation \\
Perceived Barriers & 0.003 & -0.385 & Weak negative correlation \\
\hline Perceived Self-Efficacy & 0.005 & 0.363 & Weak positive correlation \\
\hline
\end{tabular}


with the desire to quit the behavior. However, even though the respondents agree they are vulnerable to certain health and social consequences due to their status as women smokers, they do not fully believe their actions have the ability to trigger several diseases or social consequences, and these led to the low desire to stop smoking. This might have happened because the level of Perceived Susceptibility was not strong enough to make respondents stop smoking. In line with the study of Strencher et al., ${ }^{14}$ showed that only a high level of Perceived Susceptibility along with high self-efficacy would be more likely to cause smokers to reduce smoking.

The same result was observed for Perceived Severity: respondents do not fully believe their habits could have a serious impact on their health and this also led to the low desire to quit. These finding differs from the results of the studies conducted by Mohammadi et al., ${ }^{15}$ that showed there was not a significant correlation between smoking behavior and awareness of its harms. A greater feeling of risk is more likely to make an individual engage in the actions required to reduce such risk. However, on the contrary, the belief of a person in the seriousness and vulnerability to a disease does not guarantee the implementation of preventive measures.

The lower perception of respondents on the potential benefits of quit smoking has a significant correlation with the low desire of respondents to perform stop smoking behavior and vice versa. The adoption of healthy behaviors such as stop smoking has a beneficial impact on lifestyle and also encourages sharing positive testimonies to ensure others engage in similar behavior. ${ }^{16}$ The Perceived Benefit of a particular action towards reducing the risks of illness and disease influences the attitudes and behavior of an individual towards implementing such actions. ${ }^{17}$

Perceived Barriers, involving the obstacles expected during the process of quitting, was found to have a significant and inverse correlation with the desire to stop smoking behavior. This means that higher Perceived Barriers reduce the intention to quit. Perceived Barriers to smoking cessation were strongly associated with low confidence in the ability to quit smoking. According to Milcarz et al., ${ }^{18}$ the most common barriers to stop smoking were related to difficulties in quitting, such as lack of willingness, habit, stress and mood swings. A higher proportion of such barriers was found among heavy smokers compared to light smokers. There is a significant relationship between the perceptions of barriers to stop smoking and the motivation to quit. However, this factor is related to the potential negative aspects of implementing healthy actions and their physical and psychological costs.

The Perceived Belief of respondents on their ability to stop smoking was also discovered to have a significant correlation with the desire to quit. In this case, they were found not to have strong self-efficacy and this led to the low desire to engage in actions required to quit the behavior. Other studies by Poggiolini ${ }^{19}$ mentioned that the weak relation between self-efficacy and the intention to quit smoking, finding two contradicting self-efficacy effects: self-efficacy is needed to form the intention to quit, but self-efficacy might also bolster people's underestimation of their own health-related risk, thus weakening the intention to quit. Selfefficacy was reported to be a gradual process starting from an individual with the support of the surrounding environment. Bandura ${ }^{20}$ defined four important factors help in shaping self-efficacy and they include the experience of success, modeling, verbal persuasion, and emotional state. Therefore, the low self-efficacy observed in this study was possibly due to the incomplete formation of these factors.

\section{Conclusions}

The intention of stop smoking behavior among young adult women smokers in Surabaya has a significant correlation with the perceived factors of the Health Belief Model construct, which includes Perceived Susceptibility, Perceived Severity, Perceived Benefits, Perceived Barriers, and Perceived Self-Efficacy. However, all perceived variables to the intention to stop smoking show a weak positive correlation, except for Perceived Barriers variable which has a weak negative correlation. Further research is needed to support and strengthen the results of this study.

Correspondence: Shrimarti Rukmini Devy, Department of Health Promotion and Behavioral Sciences, Faculty of Public Health, Universitas Airlangga, Jl. Mulyorejo, Surabaya, Jawa Timur 60115, Indonesia.

Tel: +62315920948, Fax: +62315924618

E-mail: shrimarti-r-d@fkm.unair.ac.id

Key words: Health Belief Model; intention; stop smoking; young adult women.

Contributions: The authors contribute equally.

Conflict of interest: The authors declare no potential conflict of interest.

Funding: This study was financially supported by Sunan Ampel State Islamic University Surabaya, Indonesia.

Acknowledgments: The author thanks to the Faculty of Public Health, Airlangga University, Surabaya, Indonesia.

Conference presentation: Part of this paper was presented at the $4^{\text {th }}$ International Symposium of Public Health, 2019 October 29-31, Griffith University, Gold Coast, Australia.

Received for publication: 6 March 2020

Accepted for publication: 13 June 2020.

(Copyright: the Author(s), 2020

Licensee PAGEPress, Italy

Journal of Public Health Research 2020;9:1817

doi:10.4081/jphr.2020.1817

This work is licensed under a Creative Commons Attribution NonCommercial 4.0 License (CC BY-NC 4.0).

\section{References}

1. Perkins KA. Sex Differences in Nicotine versus Non-nicotine Reinforcement as Determinants of Tobacco Smoking. Exp Clin Psychopharmacol 1996;4:166-77.

2. World Health Organization. Global Adults Tobacco Survey: Indonesia Report 2011. New Delhi: WHO Regional Office for South-East Asia; 2012.

3. World Health Organization, CDC Foundation, World Lung Foundation. The GATS Atlas: Global Adult Tobacco Survey 2015, Myriad Editions. UK: CDC Foundation; 2015.

4. World Health Organization. Global Youth Tobacco Survey: Indonesia Report 2014. New Delhi: WHO Regional Office for 
South-East Asia; 2014.

5. Ministry of Health Republic of Indonesia. Indonesia Basic Health Research Report (RISKESDAS) 2018. Jakarta: Ministry of Health RI; 2018.

6. Allen AM, Oncken C, Hatsukami D. Women and Smoking: The Effect of Gender on Epidemiology, Health Effects, and Cessation of Smoking. Curr Addict Rep 2014;1:53-60.

7. Papadopoulos A, Guida F, Leffondre K, et al. Heavy Smoking and Lung Cancer: Are Women at Higher Risk? Results of the ICARE Study. Br J Cancer 2014;110:1385-91.

8. Huxley RR, Woodward M. Cigarette Smoking as a Risk Factor for Coronary Heart Disease in Women Compared with Men: A Systematic Review and Meta-Analysis of Prospective Cohort Studies. The Lancet 2011;378:1297-305.

9. Luo J, Margolis KL, Wactawski-Wende J, et al. Association of active and passive smoking with risk of breast cancer among postmenopausal women: a prospective cohort study. BMJ 2011;342:d1016.

10. Waylen AL, Jones GL, Ledger WL. Effect of Cigarette Smoking upon Reproductive Hormones in Women of Reproductive Age: A Retrospective Analysis. Reprod Biomed Online 2010;20:861-5.

11. Scarinci IC, Silveira AF, dos Santos DF, et al. Sociocultural Factors Associated with Cigarette Smoking among Women in Brazilian Worksites: A Qualitative Study. Health Promot Int 2007;22:146-154.

12. Mathur C, Stigler MH, Erickson DJ, et al. Transitions in Smoking Behavior During Emerging Adulthood: A
Longitudinal Analysis of the Effect of Home Smoking Bans. Am J Pub Health 2014;104:715-20.

13. Glanz K, Rimer BK, Viswanath K. (Eds.). Health Behavior and Health Education: Theory, Research, and Practice. 4th Edition. San Francisco: Jossey-Bass A Wiley Imprint; 2008.

14. Strecher VJ, Becker MH, Kirscht JP, et al. Psychosocial Aspects of Changes in Cigarette-Smoking Behavior. Patient Educ Couns 1985; 7:249-62.

15. Mohammadi S, Ghajari H, Valizade R. Predictors of Smoking among the Secondary High School Boy Students Based on the Health Belief Model. Int J Prev Med 2017;8:24.

16. Tavafian SS, Laleh H, Teamur A, et al. Prediction of Breast Self-Examination in a Sample of Iranian Women: An Application of the Health Belief Model. BMC Woman's Health Journal 2009;9:1-7.

17. Rosenstock IM. The Health Belief Model and Preventive Health Behavior. Health Educ Monogr 1974;2:354-86.

18. Milcarz K, Polańska K, Balwicki L, et al. Perceived Barriers and Motivators to Smoking Cessation Among SociallyDisadvantaged Populations in Poland. Int $\mathrm{J}$ Occup Med Environ Health 2019;32:363-77.

19. Poggiolini C, Wu Anise MS. High Self-Efficacy regarding Smoking Cessation may Weaken the Intention to Quit Smoking. Cogent Psychol 2019;6:1574096.

20. Bandura A. Self-efficacy: Toward a Unifying Theory of Behavioral Change. Psychol Rev 1977;84:191-215. 